
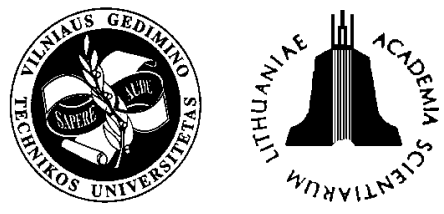

\title{
THE MODEL OF HARMFUL EJECTIONS DISSEMINATION OF THE TRANSPORT FLOWS MADE ON THE BASIS OF THE CALCULATION OF THE TURBULENT DIFFUSION EQUATION
}

\author{
Jury Komarov, Vitali Fedotov \\ Dept of Automobile Transport, Volgograd State Technical University, \\ 28 Lenin av., 400131 Volgograd, Russia.E-mail: fat@vstu.ru
}

Received 3 April 2006; accepted 9 May 2006

\begin{abstract}
Toxic gases and fine dispersive particles are pumped out into the atmosphere from a transport flow. The particles sizing less than 10,0 micro metres $\left(\mathrm{PM}_{10-2,5}\right)$ remain in the suspension for a long time due to the thermal stream and the Brownian motion; as for the surface of the layer which is between the gas molecules and solid particles - it doesn't exist. This fact allows us to study the mixture of the toxic gases and solid particles as if it is a mixture of physically homogeneous particles, and the model of their spreading can be pretended as a dissemination of a phase component in the thermodynamic system according to the diffusion laws. In this paper we refer to the calculation of the parameters of the model of the toxic ejections dissemination in the ecologically unsafe part of the main transport line. The calculation was based on the equation of the turbulent diffusion. The results of the research are intended to control the movement of the traffic on the urban mains according to ecological requirements, creating the industrial technology of refining atmospheric air of urban mains.
\end{abstract}

Keywords: transport flow, toxic gases, fine dispersed particles, harmful air pollution, dissemination model, the equation of turbulent diffusion, traffic administration, ecological requirements, harmful substance (HS).

\section{Introduction}

To control the transport on the urban mains according to ecological criteria, applying the industrial technology of active affecting the toxic gases and the fine dispersed particles of transport flows [1] we need a reliable model of the ejections of harmful air pollution (HAP) in the time and the space. At the basis of this model, which connects concentrations, the volumes and the time of the dissemination of ejections HAP into the atmosphere above the main, can be the parameters of the diffusion equation as the process of establishing inside the thermodynamic system of the equilibrium distribution of concentrations.

\section{Mathematical modulating of the dissemination processes of the harmful substances of transport flows}

The works [2,3] give the calculated expressions of the dissemination of the ejections of harmful substances, developed on the basis of the traditional theory which deals with the intensive transport flow (characteristic for the mains of megapolises) as the linear source of ejections. These expressions make it possible to determine the values of the concentrations of toxic gases and solid particles depending on the volumes of ejections, conditions of near-the-main building, the state of the atmosphere and the distance from the source of ejections in the plane.

According to the work [2], the linear source of the mass ejection of (HS) is located along the axis of a roadway of the certain direction and form of motion, in this case the maximum values of concentrations will be at the height of $0,4 \mathrm{~m}$ (for the transport flow of passenger cars) and 0,6 $\mathrm{m}$ (for the heavy trucks), and width of the maximum concentrations zone, which is identified by the intensity of turbulence $-e(0,08<e<0,27)$.

According to the work [3] minding the power of ejections of a transport flow we can calculate average values of the power of the ejections mass of transport flow and we can calculate the average values of concentrations at the height of $2 \mathrm{~m}$. The width of ejections zone is taken as the equal to the width of main. It is insufficient for establishing the volumes of air, which needs refining in the real time. It is necessary to know the velocity of HS dissemination and the volumes of the airspace, which covers the ecologically unsafe parts of the urban highway (main and near-the-main zone), contaminated by toxic gases and solid particles.

Nowadays there is a large quantity of calculated 
expressions and procedures, which describe laws governing the formation and scattering of the harmful impurities in air. These expressions are based on the solutions of the equation of turbulent diffusion. In this case it is considered that in the direction of the motion of a transport flow the volumes of ejections depend on the intensity and organization of motion, the type of transportation means (sources of ejections), and, therefore, the concentration of HAP remains constant in the sufficiently extensive sections ( $1-2 \mathrm{~km}$ ) of urban mains. In that case, the process of HAP dissemination in the air in the section of urban highway in the directions of the perpendicular to the direction of the motion of a transport flow can be examined as the regulated motion of molecules which emerged due to the leveling off of heterogeneity in the air density, which arose in the lowest layer of the atmosphere at the entire length of the highway zone because of the ejections made by the transport flows of toxic gases and microscopic particles. The directed mass transfer of substance (diffusion) establishes the equilibrium distribution of concentrations in the system during a certain period of time. If the system is affected by external forces, in particular, wind or difference of temperatures, then the results of diffusion are affected by the concentration gradients, which appear in the direction of the action of external forces.

A change of the HAP concentration in the system in the one-dimensional case $(c=S(x) p(x))$ in the course of time $t$ is described by the differential equation (first Fick law) [4]:

$$
d M=-k^{(j)} D \frac{d \rho}{d x} d S d t,
$$

where $d M$ is the component mass which is transferred during the time equaling $d t$ through the elementary zone $d S$ in the direction $-x$ to the above mentioned zone in the way if diminishing its density; $d p d S / d x$ is the concentration gradient, $D$ - diffusion coefficient, $k^{(j)}$ coefficient, which considers the influence of the $j$ external forces, applied in the direction of the normal transfer.

Besides the ejections of the worked-out gases, the transport flow produces a cloud of dust, that consists of more than $60 \%$ of the microscopic and ultramicroscopic particles within the radius of $10,0-0,25 \mathrm{~m}$ and less, which are formed as a result of the abrasion of wheels (during the cohesion with the road) and cover plates of brake shoes (with the braking). According to the data [5] the particles of the size less than 10,0 micro metres $\left(\mathrm{PM}_{10-2,5}\right)$, under the effect of the air heat fluxes and the Brownian motion prolonged time, are located in the suspension. The surface of the layer, situated between the molecules of gas and the solid particles is absent. More than that, the time of natural coagulation and sedimentation of particles in these sizes are defined by tens of hours and compared with the time of the dissemination of gaseous components. It made possible to consider the mixture of toxic gases and solid particles as one phase of the physically uniform particles in the thermodynamic system and to summarize concentration of phase and its components and to calculate the same equitation taking into account the mass of components in the system.

Thus, the model of the HAP ejections dissemination in the time in air (in the ecologically unsafe zones having length $l$ ) can be examined as the process of distributing the concentration of $c(x, z, t)$ in the directions $(x, z)$ of the normal transfer of the pollution from the surfaces of line source, on which at the initial moment of time $t_{H}$ the mass $M$ of ejections (per unit of the area of the corresponding surface), (Fig 1) is concentrated. In this case the height of the side of line source can be accepted to the equal height of the surface with the maximum concentrations $H$ and, taking into account that moving in the dense flow transportation means actively influence the mixing of the HAP train of each automobile, the width of line source - to average width of transport flow $b$.

Integrating the expression (1), we will obtain the expression for the simulation of concentrations $C$ in the surface boundary layer of the free space in the appropriate directions of the normal transfer taking into account the time of the dissemination $t$ :

$$
C(x, z, t)=\frac{M_{x, z}}{\sqrt{\pi k_{x, z}^{(j)} D t}} e^{-\frac{a_{x, z}{ }^{2}}{4 k_{x, z}^{(j)} D t}},
$$

where $M_{x z}$ is mass of ejections $Q$, led to the unit surface area of line source $S_{x, z}$, which corresponds to the direction of the normal transfer, and up to the initial moment of time $t_{H} \rightarrow 0 ; a_{x, z}$ - the distance from the surface with the maximum concentrations in the direction of the corresponding standard of transfer.

The coefficient of the diffusion $D$ is determined from the reorganized equation of elementary kinetic theory of gases [4]:

$$
D=\frac{1}{3} \frac{u}{\sqrt{2} n_{0} \sigma}=\frac{1}{3} u \lambda,
$$

where $u$ is the average speed of the thermal motion of the molecules of toxic gases in usual conditions; it equals to $400-460 \mathrm{~m} / \mathrm{s} ; \lambda$ - means free path, equal to $0,084 \times 10^{-5} \mathrm{~m} ; \sigma=\pi d^{2}-$ an affective cross section; $n_{0}=n / V-$ number of molecules in $1 \mathrm{~cm}^{3}$, equals to $2,687 \times 10^{19} 1 / \mathrm{cm}^{3}$.

At these initial data settlement factor of diffusion $D=(1,1-1,3) \times 10^{-4} \mathrm{~m}^{2} / \mathrm{s}$. 


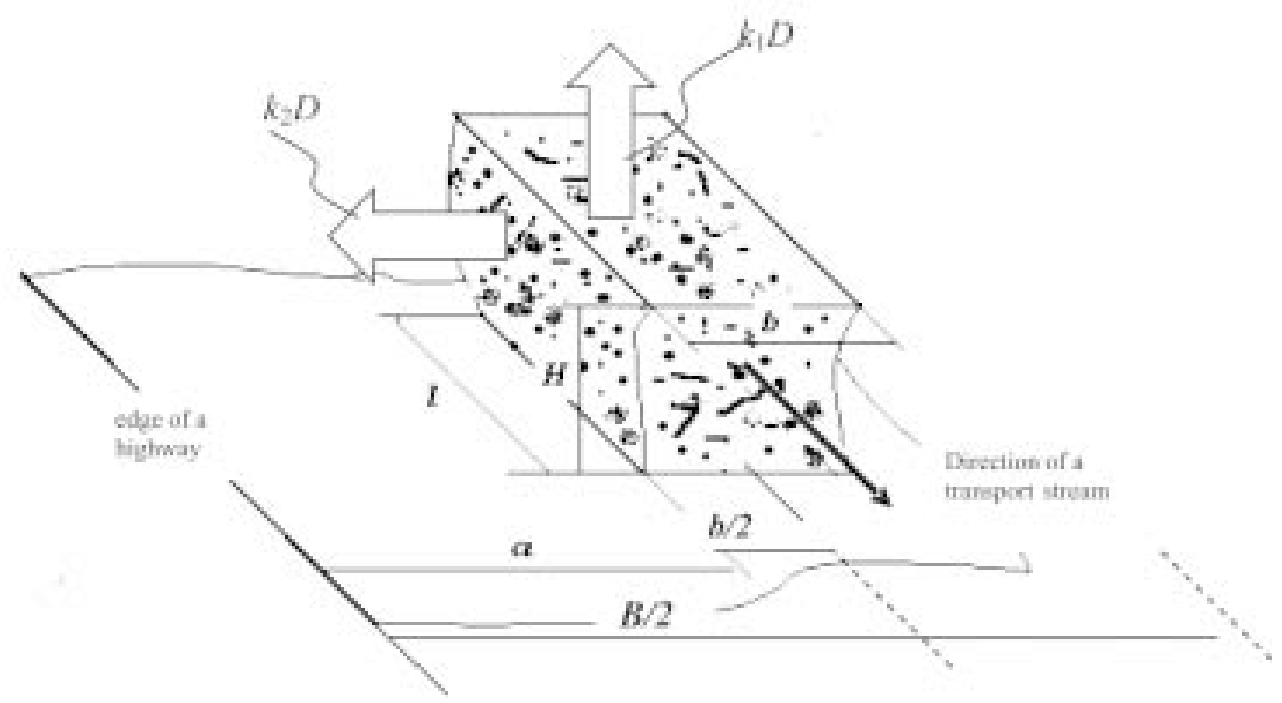

Fig 1. The scheme of a fragment of a linear source of harmful substance emissions (at one-way traffic) on a highway in width $B$

Factor $k^{(j)}{ }_{x, z}$ considering influence of external forces in a corresponding direction of carry, we shall define proceeding from that $a_{x, z}$ - the distance from a conditional surface of a linear source to which during the initial moment of time weight is concentrated $M_{x, z}$ emissions, is equal to 0 .

In this case, the expression (2) will become:

$$
C_{a=0}=\frac{M_{x, z}}{\sqrt{\pi k_{x, z}^{(j)} D t}}=\frac{Q}{S_{x, z} \sqrt{\pi k_{x, z}^{(j)} D t}},
$$

where $C_{a=0}$ is concentration HS, $\mathrm{mg} / \mathrm{m}^{3}$ (pays off on [2] $\mathrm{c}-$ the account of intensity and modes of movement, a kind of a transport stream, conditions of buildings); $t$ time of measurements, (at natural researches of equally 30 mines $\left(0,18 \times 10^{4} \mathrm{~s}\right)$. For such duration the initial moment $t H \rightarrow 0$ can be accepted for practical calculations equal to $1 \mathrm{~s}$; $Q$ - settlement quantity of emissions HS, mg on $1 \mathrm{~m}$ of length of a highway in $1 \mathrm{~s}$. (for the same site of a highway); $S_{x, z}$ - the area of a surface of a linear source to which the corresponding normal carry of pollution is enclosed, $\mathrm{m}$.

\section{Calculation of the parameters of the model of the harmful ejections dissemination in the ecologically unsafe parts of urban main}

The results of the previously carried out research by the Dept of Automobile Transport and calculations in the ecologically unsafe parts of urban highway [6] showed: with the intensity of the adjustable motion of $320-400$ aut $/ \mathrm{h}$ to the strip (not less than $70 \%$ passenger motor transport) the ejections of the basic components of the waste gases $-\mathrm{CO}, \mathrm{CnHm}, \mathrm{NO}_{\mathrm{x}}$ on the mains with 2-3 strips in each direction can be within the limits, respectively: $72,7-90,8 \mathrm{~kg} / \mathrm{km} \mathrm{h} ; 5,2-6,6 \mathrm{~kg} / \mathrm{km} \mathrm{h}$;
$10,4-13,0 \mathrm{~kg} / \mathrm{km} \mathrm{h}$; the calculated volumes of the cloud of dust comprise: $0,03-0,05 \mathrm{~kg} / \mathrm{km} \mathrm{h}$ (particles of the wear of the brake linings), $0,15-0,20 \mathrm{~kg} / \mathrm{km} \mathrm{h}$ (tire dust).

Control measurements (in the summer period, the day hours) showed that the average values of $\mathrm{CO}$ concentrations (at the edge of a main at the height from 0,5 to $4 \mathrm{~m}$ ) did not exceed $3,7-5,6 \mathrm{mg} / \mathrm{m}$; the general concentration of solid particles composes 0,28 $0,41 \mathrm{mg} / \mathrm{m}$, the concentration of solid particles with the sizes is less than $10 \mathrm{~m}$ of $0,14-0,24 \mathrm{mg} / \mathrm{m}$.

The summary concentration of the toxic components of the waste gases and solid particles $C_{\max }$, determined according to those recommended in $[2,3]$ formulas in the section of highway pointed out above with the length of $l=1000 \mathrm{~m}$ and with the width of $b=10 \mathrm{~m}$, the average width of transport flow $0,5-0,6 \mathrm{~m}$ with the density of the motion of $50-60 \mathrm{veh} / \mathrm{km}$ ) for the conditions of near-the-main building (average height 7-12; the density of building 70-80\%) and usual speeds of wind $2-5 \mathrm{~m} / \mathrm{s}$, comprised $31,6-40,7 \mathrm{mg} / \mathrm{m} \mathrm{[2]} \mathrm{for}$ mass of ejections, concentrated in the volume of the line source, and $3,0-3,5 \mathrm{mg} / \mathrm{m} \mathrm{[3}$ ] at the height of $2 \mathrm{~m}$ at the edge of main.

We calculated the parameters of the ejections model in the following order. Taking into account that the maximum of pollution under the action of turbulence depending on the stratification and speed of the wind of air displaces [2], in the beginning according to the formula (4) let us determine $k_{x}$ (the normal transfer is applied to the side of the line source with the height of $H$, Fig 1). Further on (2) we calculate the HS concentrations in the volume limited by height $H$ and the edge of the main in the direction of the same standard of transfer. Since the level of the plane of ejections is located at the height $H$, which is the point of the maximum concentrations, then, for our case, HS 
concentrations on this surface can be examined as maximum ones. Applying the normal transfer to this surface and using expression (2), let us determine $k_{z}$.

Thus, the model of ejections for the section of the main pointed out above will take the form:

$$
c(z, t)=(2,1-5,2) e^{-\frac{a_{z}^{2}}{4 \cdot 6,3 \cdot 1,2 \cdot 10^{4} t} .}
$$

In Table and Fig 2 results of calculations of parameters of the equation (4) for modeling diffusion of emissions HS for ecologically unsafe site of a highway and schedules of special cases of model of emissions are presented, accordingly.

The average values of harmful ejections concentrations, which had been obtained as a result of control measurements and calculations using the developed model, made up respectively $3,7-5,6 \mathrm{mg} / \mathrm{m}^{3}$ and $1,8-3,7 \mathrm{mg} / \mathrm{m}^{3}$ at a height $0,4-4,0 \mathrm{~m}$ at ecologically unsafe site of the urban highway. Taking into account metrological capacities of control equipment and made physical and mathematical assumptions, differences in the values of concentrations can be considered non significant.

\section{Conclusions}

Specifics of natural coagulation and sedimentation of solid particles sizing less than 10,0 micro metres $\left(\mathrm{PM}_{10-2,5}\right)$, weighted in the air of an urban highway, permits to consider the mixture of toxic gases and solid particles as the single component of a phase in the thermodynamic system, the concentration of which is fixed as a result of the directed transfer of mass of substance (diffusion). The calculation carried out on the basis of the equation of turbulent diffusion of parameters of the model of harmful ejections dissemination and the concentrations control measurements at the same ecologically unsafe site of the urban highway (with account of the metrological capacities of the control equipment and the made physical and mathematical assumptions) have shown the insignificance of their value differences.

Results of calculation of parameters of the model of harmful emissions distribution

\begin{tabular}{|c|c|c|c|c|c|}
\hline $\begin{array}{c}\text { Height of } \\
\text { a lateral } \\
\text { surface of } \\
\text { a linear } \\
\text { source, } \\
H, \mathrm{~m}\end{array}$ & $\begin{array}{c}\text { Width of a } \\
\text { horizontal } \\
\text { surface of a } \\
\text { linear } \\
\text { source, } b, \\
\mathrm{~m}\end{array}$ & $\begin{array}{c}\text { The factor } \\
\text { considering influence } \\
\text { of external forces in } \\
\text { the direction from a } \\
\text { normal to a lateral } \\
\text { surface, } k_{\mathrm{x}}\end{array}$ & $\begin{array}{c}\text { Distance from a } \\
\text { lateral surface of a } \\
\text { linear source up to } \\
\text { the edge of a } \\
\text { highway, } \\
x, \mathrm{~m}(x=B / 2-b / 2)\end{array}$ & $\begin{array}{c}\text { Harmful substance } \\
\text { concentration on a } \\
\text { surface in the } \\
\text { limited height } H \\
\text { and the edge of a } \\
\text { highway, } \\
C_{\max }, \mathrm{mg} / \mathrm{m}^{3}\end{array}$ & $\begin{array}{c}\text { The Factor considering } \\
\text { influence of external } \\
\text { forces in the direction } \\
\text { from a normal to a } \\
\text { horizontal surface, } k_{\mathrm{z}}\end{array}$ \\
\hline 0,4 & $0,5-0,6$ & $4,3-7,1$ & 4,7 & $2,1-5,2$ & $1,9-11,7$ \\
\hline
\end{tabular}

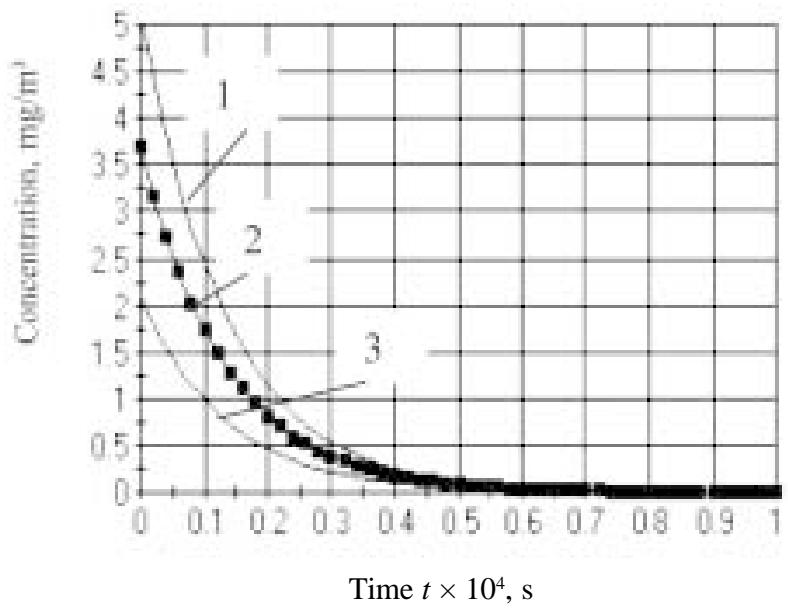

a)

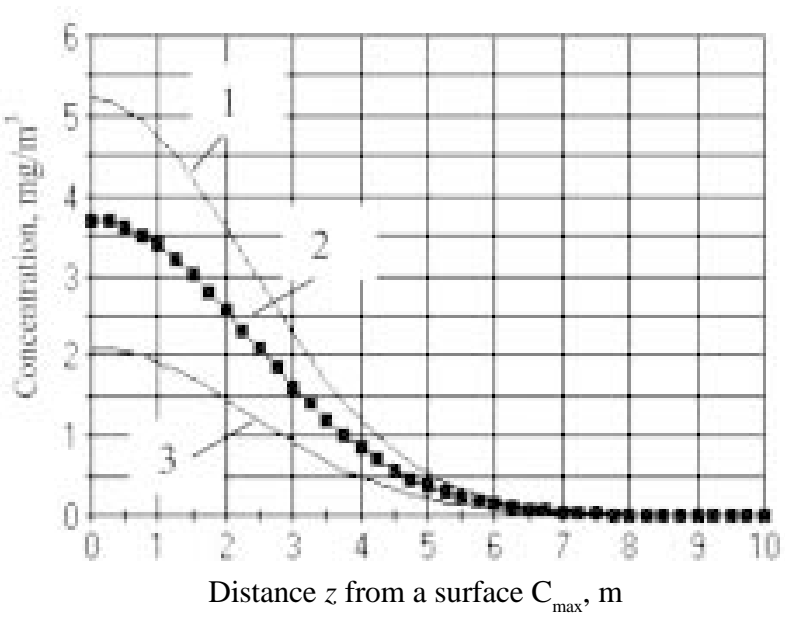

b)

Fig 2. Distribution of concentration of harmful substance emissions at the edge of passage parts on time (a) on $H=0,5 \mathrm{~m}$ and on height (b) for $1 \mathrm{~h}$ on ecologically unsafe site of a highway:

1 - the schedule of the equation of diffusion for $C_{\max }=5,2 \mathrm{mg} / \mathrm{m}^{3} ; 2$ - the schedule of the equation of diffusion for $C_{\max }=3,7 \mathrm{mg} / \mathrm{m}^{3}$ (compare value); 3 - the schedule of the equation of diffusion for $C_{\max }=2,1 \mathrm{mg} / \mathrm{m}^{3}$ 
The research results are designed for traffic control of automobile transport at urban highways according to environmental requirements, creation of an industrial technology of clearing the open air at urban highways.

\section{References}

1. Komarov, J. J.; Fedotov, V. N. Technology of active influence on toxic gases and firm particles of automobile transport streams. Mobile technics (Moбильная техника), No 3, 2004, p. 45-48 (in Russian).

2. Ecological safety of transport streams. Edited by A. B. Djakov (Экологическая безопасность транспортных потоков. Под ред. А. Б. Дьякова). Moscow: Transport, 1989. 128 p. (in Russian).

3. Denisov, V. N.; Rogalev, V. A. Problem of ecologization of motor transport (Проблемы экологизации автомобильного транспорта). Sankt-Petersburg: MANEB, 2003. 213 p. (in Russian).

4. Javorskij, B. M.; Detlaf, A. A. Director on the physics (Справочник по физике). Moscow: Science, 1977.943 p. (in Russian).

5. Kiselyov, N. D. Clearing of air from high dispersive dust by method of artificial ionization (Очистка воздуха от высокодисперсной пыли методом искусственной ионизации). Moscow: Mechanical Engineering, 1966. 71 p. (in Russian).

6. Gudkov, V. A.; Fedotov, V. N. Limiting of a number of passenger vehicles by criterion of ecological safety. Standards and Quality (Стандарты и качество), № 2, 2003, p. 52-54 (in Russian). 